Itinerari geològic i geoambiental per les comarques del Baix Llobregat i del Vallès Occidental: des d'Olesa de Montserrat a Ribes Blaves, a Sant Pere Sacama, al Coll Ventós i a Olesa de Montserrat

Josep Maria Mata-Perelló

Joaquim Sanz Balagué

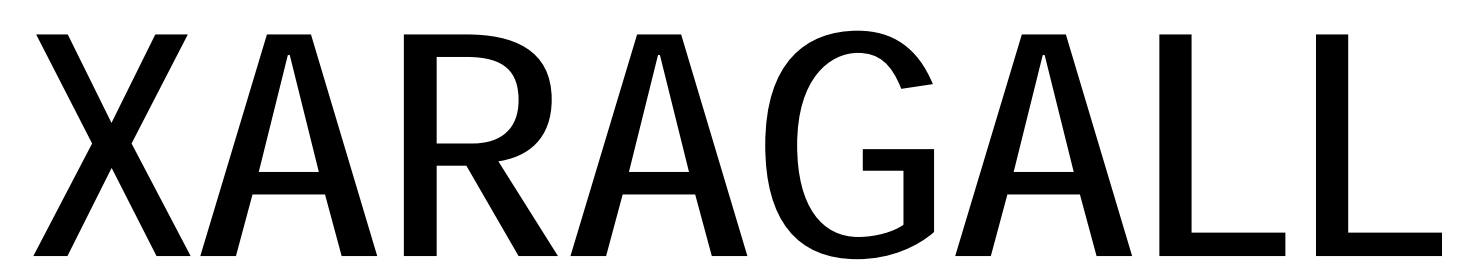

REVISTA DE CIÈNCIES DE LA CATALUNYA CENTRAL

n. 4

ABRIL 2014

Com citar l'article: Mata-Perelló, JM.; Sanz Balaguer, J.. Itinerari geològic i geoambiental per les comarques del Baix Llobregat i del Vallès Occidental: des d'Olesa de Montserrat a Ribes Blaves, a Sant Pere Sacama, al Coll Ventós i a Olesa de Montserrat. A: XARAGALL. Revista de Ciències de la Catalunya Central. 2014. (n.4). ISSN 1131 - 5385 DL: B.36.662 - 82 DOI 


\title{
ITINERARI GEOLÒGIC GEOAMBIENTAL PER LES COMARQUES DEL BAIX LLOBREGAT I DEL VALLÈS OCCIDENTAL: DES D’OLESA DE MONTSERRAT A RIBES BLAVES, A SANT PERE SACAMA, AL COLL VENTÓS I A OLESA DE MONTSERRAT
}

\author{
Josep Maria Mata-Perelló \\ Museu de geologia Valentí Masachs, Escola Politècnica Superior d'Enginyeria de Manresa \\ (EPSEM), Universitat Politècnica de Catalunya · BarcelonaTech (UPC), 08272 Manresa, Spain
}

\section{Joaquim Sanz Balagué}

Departament d'Enginyeria Minera i Recursos Naturals (EMRN), Escola Politècnica Superior d'Enginyeria de Manresa (EPSEM), Universitat Politècnica de Catalunya - BarcelonaTech (UPC), 08272 Manresa, Spain

Paraules clau: materials miozènics; Paleozoic; Depressió prelitoral catalana; Serralada prelitoral catalana; Mesozoic; Patrimoni miner; Patrimoni geològic

\section{Resum}

Itinerari realitzat el dia 20 d'abril del 2013. En aquesta ocasió, el recorregut del present itinerari discorre en la seva major part pel Sistema Mediterrani (una de les tres unitats geològiques que constitueixen el nostre país), i més concretament per dues de les seves sotsunitats més externes: la Serralada Prelitoral Catalana (per on discorrerà la major part del recorregut i on finalitzarà) i per la Depressió Prelitoral Catalana (per on s'iniciarà el recorregut). Tot i així, molt puntualment, també es passarà per la Depressió Geològica de I’Ebre.

També cal dir, que el recorregut de l'itinerari s'efectuarà per les comarques del Vallès Occidental i la del Baix Llobregat principalment, ambdues de la la Regió (o Regió de Barcelona).

Així, el recorregut s'iniciarà a la població d'Olesa de Montserrat i tot seguit el recorregut es desplaçarà cap als indrets de Ribes Blaves, Sant Pere Sacama, el Coll Ventós, per a retornar finalment cap a Olesa de Montserrat, per on finalitzarà. 


\section{Objectius fonamentals d'aquest itinerari}

Els objectius fonamentals que es pretenen aconseguir en aquest itinerari, es poden concretar en els següents aspectes generals:

1. Observació de l'estructura de la Depressió Prelitoral Catalana (del Sistema Mediterrani), per on s'efectuarà el primer tram del recorregut, entre Olesa de Montserrat i el paratge de Ribes Blaves. I també al final del recorregut.

2. Observació dels materials miocènics que constitueixen la Depressió Prelitoral Catalana.

3. Observació de l'estructura de la Serralada Prelitoral Catalana, per la qual discorrerà la major part de recorregut del present itinerari, entre Ribes Blaves, Sant Pere Sacama i Olesa de Montserrat.

4. Observació dels materials paleozoics (de l'Ordovicià i del Silurià) i dels mesozoics (exclusivament del Triàsic), els quals constitueixen la Serralada Prelitoral Catalana, pels indrets on discorrerà el recorregut de l'itinerari, entre els indrets anteriorment esmentats.

5. Observació de la Depressió Geològica de l’Ebre i dels materials cenozoics que la reblen. La trobarem molt puntualment, al Pla del Fideuer, al terme de Vacarisses (Vallès Occidental).

6. Observació de les relacions estructurals entre les dues unitats geològiques acabades d'esmentar: entre la Depressió Prelitoral Catalana i la Serralada Prelitoral Catalana.

7. Observació al llarg del recorregut (i a distancia) dels impactes creats per les obres públiques (com l'Autopista) i per les explotacions mineres (la pedrera de Coll Cardús). I en tot cas: observació de les restauracions dutes a terme, si es dóna el cas.

8. Observació, al llarg del recorregut dels indrets relacionats amb el Patrimoni Geològic. Així, cal fer esment dels interessants paratges de Ribes Blaves i Sant Pere Sacama, entre altres.

9. Observació, al llarg del recorregut dels indrets relacionats amb el Patrimoni Miner. Així, caldrà fer esment de les restes de la Teuleria de Sant Pere Sacama.

\section{Antecedents bibliogràfics}

Pel que fa als antecedents relacionats amb altres itineraris geològics, que discorrin per aquesta zona, ens referirem a diferents treballs nostres: Mata-Perelló $(1984,1995,1996,1999,2001$, 2006, 2007, 2009 i 2012). Fora d'aquests, no en coneixem cap altre.

Pel que fa amb els treballs relacionats amb els caràcters generals de la geologia de la zona, ens referirem als següents antecedents: Guimerà et altri (1992), , RIBÁ (1976).

Més endavant, dintre de l'apartat dedicat a les referencies bibliogràfiques ja ens referirem a tots ells.

\section{Recorregut de l'itinerari}

El recorregut del present itinerari començarà dintre del Baix Llobregat, a la població d’Olesa de Montserrat, per on es realitzaran las primeres aturades d'aquest itinerari. 
Després, el recorregut es dirigirà cap als paratges de Ribes Blaves (per on s'efectuarà una aturada). Aquest recorregut caldrà fer-lo amb molta cura pel costat de la carretera.

Tot seguit, el recorregut es dirigirà cap als paratges de Sant Pere Sacama, des d'on s'anirà cap al Coll. En aquest tram (el central de tot el recorregut) es realitzaran diverses aturades. Posteriorment, es baixarà cap a Olesa de Montserrat, per on finalitzarà aquest recorregut efectuat totalment a peu. Aquest darrer tram, caldrà fer-ho amb molta cura, pel costat de la carretera.

\section{Advertiment previ}

Com en altres recorreguts de recerca geològica i mineralògica ..., si es disposa del temps suficient, poden efectuar-se passant per totes les parades i filloles. En cas contrari, recomanem prescindir de les anomenades parades - condicionals.

En aquesta ocasió, el recorregut s'efectuarà a peu, tot anant per corriols i senders. Tot i així, una part del recorregut es realitzarà pel costat de la carretera, per la qual cosa, es fonamental de tenir la suficient cura. Això succeirà entre Olesa de Montserrat i Ribes Blaves i entre el Coll Ventós i Olesa de Montserrat, al principi i a la fi del recorregut.

A l'igual que als altres itineraris realitzats fins ara, recomanem tenir la màxima cura de respecte cap al Medi Natural i cap al Medi Ambient al llarg de tot el recorregut, i també fora d'ell.

\section{Descripció de l'itinerari}

Com de costum, estructurarem el recorregut de l'itinerari en una sèrie de PARADES, que tot seguit anirem veient. En cadascuna d'aquestes aturades farem un breu comentari (geològic 0 mineralògic, segons s'escaigui).

En cada cas indicarem, entre parèntesi el full topogràfic del "Mapa Topogràfico Nacional" a escala 1:50.000, de I'Instituto Geográfico Nacional, on es troba l'aturada, que en aquest cas seran sempre els fulls 391 (o d'Igualada) i 392 (dit de Sabadell).

Així doncs, la relació ordenada de les parades que composen aquest itinerari, és la següent:

\subsection{Parada 1 - condicional. Sortida d'Olesa de Montserrat cap a Terrassa (terme municipal d'Olesa de Montserrat, comarca del Baix Llobregat, subcomarca del Baix Llobregat - Nord ). (Full 392).}

El recorregut de l'itinerari començarà a la població d'Olesa de Montserrat, al bell mig de la ciutat. Concretament, I'iniciarem a l'Estació dels Ferrocarrils Catalans, al seu aparcament.

Aquesta població es troba dintre de la Depressió Prelitoral Catalana, entre afloraments dels materials cenozoics del Miocè que la reblen. Tot i així, aquests materials no es fan palesos, ja que es troben recoberts per sediments terrígens del Quaternari. Així, la ciutat d'Olesa es troba totalment situada sobre aquests darrers materials. 


\subsection{Parada 2. Paratge de Ribes Blaves, (terme municipal d'Olesa de Montserrat, comarca del Baix Llobregat, subcomarca del Baix Llobregat - Nord). (Full 392).}

Després de fer l'aturada anterior, cal sortir d'Olesa de Montserrat, per la carretera que es dirigeix cap a Terrassa i Vacarisses (la B - 120). En arribar a l'indret de Ribes Blaves, farem la primera aturada, després de recórrer uns $4 \mathrm{Km}$ des de l'inici del recorregut a la parada anterior.

En aquest trajecte, en un principi hem anat trobant els materials esmentats a la parada anterior, els quals sovint s'han trobat recoberts per terrenys detrítics quaternaris. Tot i així, prop de l'indret de l'aturada s'han anat trobant afloraments dels materials paleozoics de l'Ordovicià. Aquests materials paleozoics estan constituïts per fil-lites vinoses, metapsamites o gresos metamorfitzats, i esquists grisos i negres. Uns i altres estan, sovint, travessats per filons de quars.

L'indret de Ribes Blaves, on estem ara situats, està ubicat sobre la falla que posa en contacte els materials paleozoics amb els miocènics que constitueixen la Depressió del Vallès (nom local de la Depressió Prelitoral Catalana). Aquest nom "Ribes Blaves", ve del color que prenen els materials de la bretxa de falla, procedents de la trituració d'esquists i psammites. La falla en qüestió, té una direcció E-W, constitueix el contacte entre la Serralada Prelitoral i la Depressió abans esmentada, essent el seu salt de més de $2000 \mathrm{~m}$ (d'acord amb els sondejos fets al Vallès). La bretxa de falla té una amplada de quasi $100 \mathrm{~m}$, i està formada per materials paleozoics trinxats i triturats, entre els quals es troben alguns tascons, formats per esquists, sense triturar.

Per d'altra banda, es molt interessant veure la típica morfologia de "Bad-lands" o Xaragalls, desenvolupada entre els materials que formen la bretxa de falla. Sense cap mena de dubte, aquest indret constitueix un immillorable exemple de l'esmentada morfologia. Sobre els materials paleozoics trinxats, s'han originat profundes torrentades, que es dirigeixen majoritàriament cap a la Riera de Sant Jaume. Relacionats amb els xaragalls, és freqüent trobar bons exemples d'estructures piramidals.

També és interessant observar la forta erosió remuntant de la Riera de Sant Jaume, en direcció W, que a la llarga pot arribar a la captura del Torrent de Coll Blanc, que fa el desguàs de Ribes Blaves per la seva part occidental. L'esquema és el següent (esquema 1 i fotografia 1).

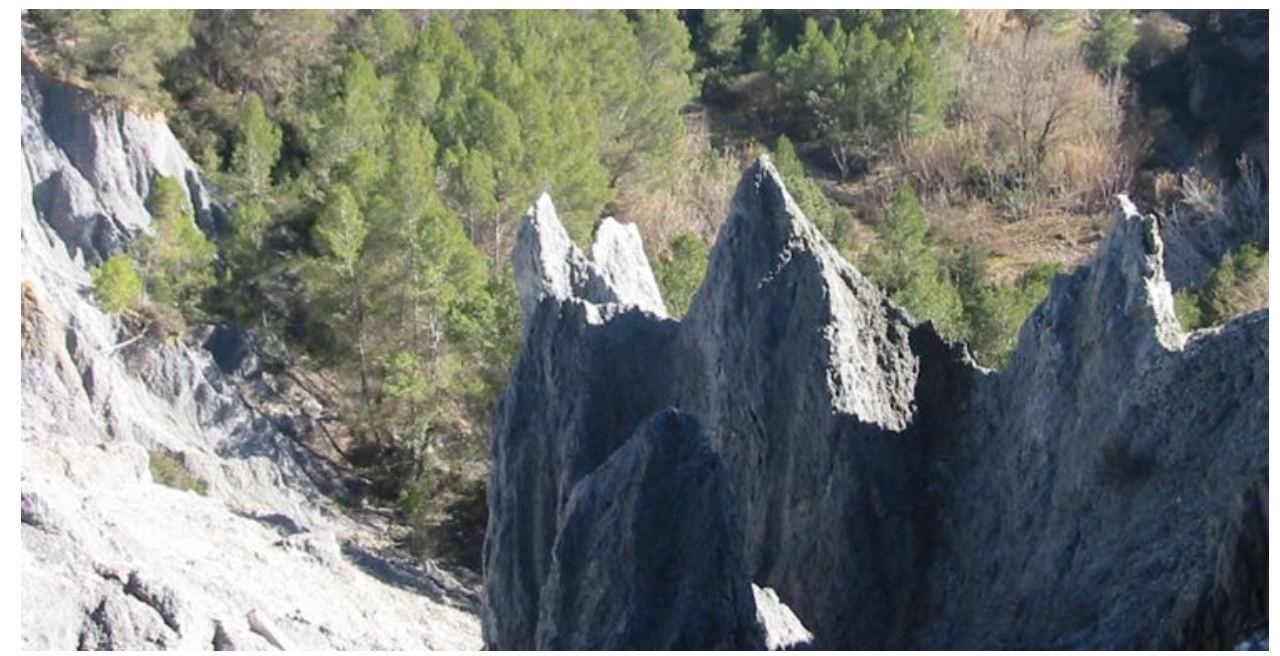

Fotografia 1. Aspecte dels xaragalls desenvolupats a Ribes Blaves, sobre la milonita de la falla d'Olesa de Montserrat a Ribes Blaves, a Sant Pere Sacama, al Coll Ventós i a Olesa de Montserrat 


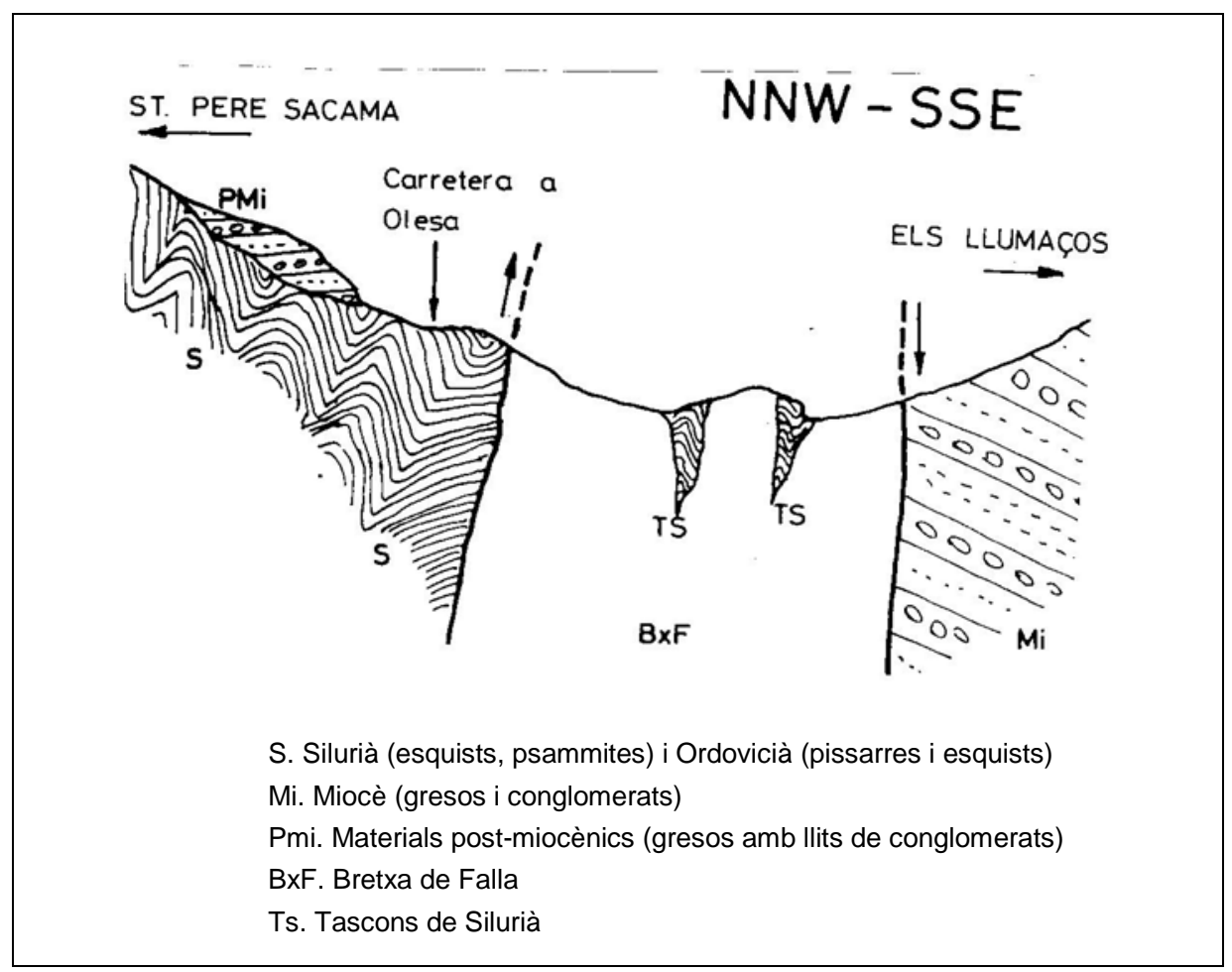

Esquema 1 Tall reproduït de MATA-PERELLÓ (1984a)

\subsection{Parada 3. La Teuleria de Sant Pere Sacama, (terme d'Olesa de Montserrat, comarca del Baix Llobregat, , subcomarca del Baix Llobregat - Nord). (Full 392).}

Des de la parada anterior, cal continuar per la carretera que es dirigeix cap a Terrassa. A uns $0^{\prime} 2 \mathrm{Km}$ es trobarà un trencall, per l'esquerra, que ens caldrà agafar, per tal de continuar per aquest camí-carreter, que en uns $2 \mathrm{Km}$ arriba fins a l'ermita romànica de Sant Pere Sacama. $\mathrm{A}$ uns $300 \mathrm{~m}$ abans d'arribar-hi, farem una nova aturada en una antiga teuleria, recentment restaurada. Així, des de la parada anterior, haurem recorregut gairebé uns $1 ` 5 \mathrm{Km}$.

Al Ilarg d'aquest recorregut, des de la parada anterior, tot mirant cap al Sud i cap al SE, es poden veure les diferents unitats geològiques que configuren els Catalànids (o Sistema Mediterrani). Així, en primer terme es pot veure la Serralada Prelitoral Catalana (on ara estem situats). Més enllà es pot veure la Depressió Prelitoral Catalana (on es situen les properes poblacions d'Olesa, Abrera i Esparreguera). Més enllà es pot veure la Serralada Litoral Catalana (amb els relleus del Bloc de Garraf i de Collserola). I fins i tot, més enllà es pot veure la Depressió Litoral Catalana (amb el delta del Llobregat). En aquest recorregut, fins arribar a la cruïlla, s'han anat tallant els materials paleozoics, els quals es troben constituïts per nivells d'esquistos i de llicorelles. Així, tot aquest recorregut, s'haurà efectuat entre els materials paleozoics de la Serralada Prelitoral Catalana, constituïts per nivells de pissarres que pertanyen primer al Silurià, i després a I'Ordovicià. Aquests materials es troben sovint travessats per petits filonets de quars, i també per falles. Per d'altra banda, es poden trobar bons exemples de plecs en knick i plecs en chevron, com els que es poden veure a uns $300 \mathrm{~m}$ de l'inici d'aquest camí ( fotografia 2). 


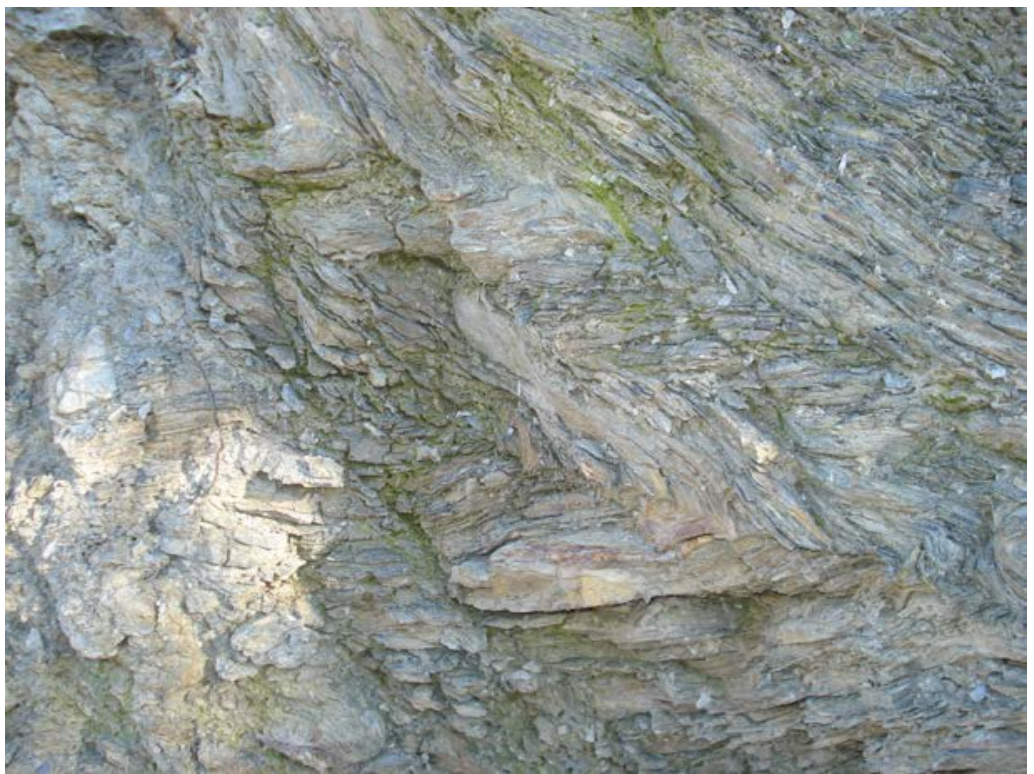

Fotografia 2. Aspecte de les fracturacions i dels plecs entre els materials de I'Ordovicià

Sovint, aquests materials es troben recoberts per derrubis de pendents, formats per fragments de pissarres, sovint alterades i meteoritzades a argiles. Precisament, en aquest indret han estat utilitzats aquests materials per a la fabricació de teules. Així, ara veiem una vella teuleria, recentment restaurada. (fotografies 3 i 4).

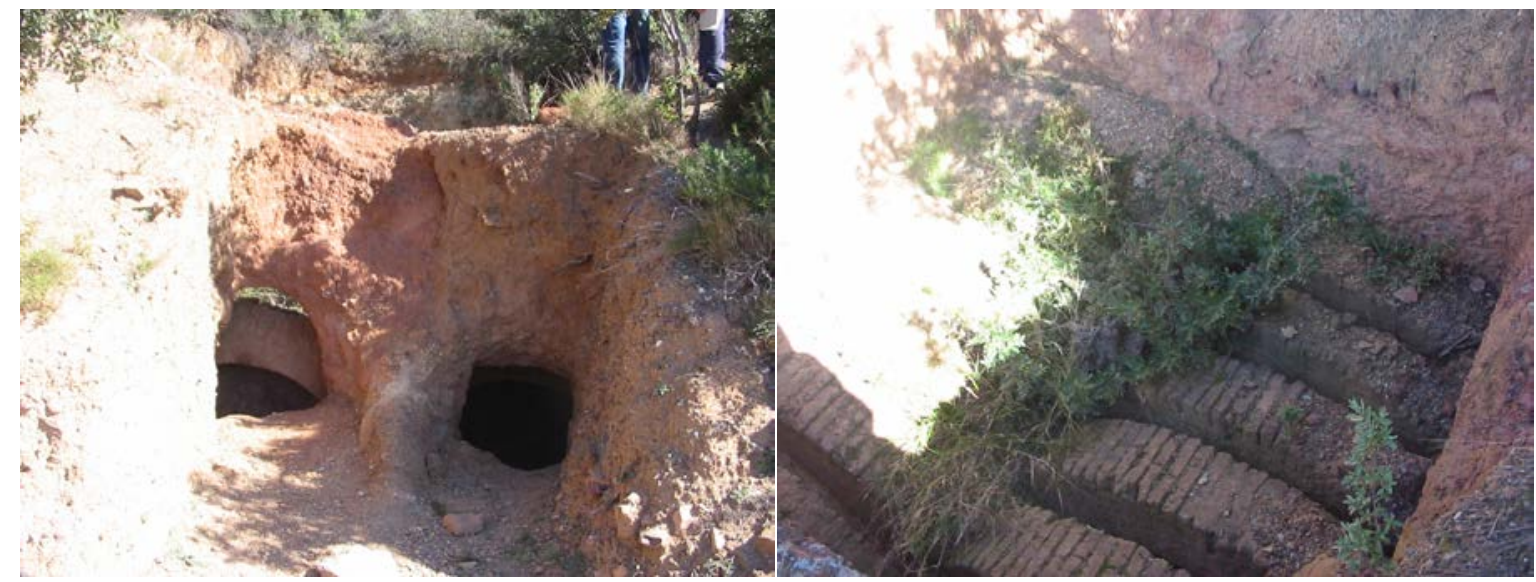

Fotografia 3. Restes de la Teuleria de Sant Pere Sacama

Fotografia 4. Un altre aspecte de la teuleria restaurada

Cal dir que aquesta teuleria es un element molt important del nostre Patrimoni Miner, que cal conservar. d’Olesa de Montserrat a Ribes Blaves, a Sant Pere Sacama, al Coll Ventós i a Olesa de Montserrat 


\subsection{Parada 4. Ermita de Sant Pere Sacama, (terme municipal d'Olesa de Montserrat, comarca del Baix Llobregat, subcomarca del Baix Llobregat - Nord). (Full 392).}

Des de la parada anterior, cal continuar pel camí que es dirigeix cap a l'ermita romànica de Sant Pere Sacama. A uns 300 metres, després d'haver fet l'altra parada hi arribarem. Aquí, farem una nova aturada.

En aquest recorregut, fins arribar-hi, haurem anat trobant els materials esmentats al trajecte anterior: els materials paleozoics constituïts per nivells d'esquistos i de llicorelles. Així, tot aquest recorregut, s'haurà efectuat de nou entre els materials paleozoics de la Serralada Prelitoral Catalana. Aquests materials es troben sovint travessats per petits filonets de quars, $\mathrm{i}$ també per falles.

A l'ermita de Sant Pere Sacama, es troba el contacte discordant entre els materials paleozoics anteriorment esmentats (els quals pertanyen molt probablement a l'Ordovicià i al Silurià) i els nivells inferiors mesozoics (els quals pertanyen al Triàsic Inferior; és a dir al Buntsandsteim). En aquest indret, els conglomerats basalts del Buntsandsteim apareixen en situació vertical. Donada la seva resistència a l'erosió destaquen sobre els materials circumdants, produint la formació d'hogbacks o d'espases. Precisament, sobre una d'aquestes espases es on es troba situada i enlairada l'ermita de Sant Pere Sacama, on ara ens trobem.

També cal dir que aquests conglomerats són de caràcter quasi exclusivament quarsífer, amb ciment i matriu silícica. Per d'altra banda, cal dir que sovint contenen petits creixements de BARITINA, situats entre el ciment silici.

Precisament, des del darrere de l'ermita, es possible veure els indrets de l'esmentada aturada. Tanmateix es pot veure l'aflorament gairebé continuat dels materials basals del Buntsandsteim, entre aquella parada i la present. L'esquema d'aquests contacte, és el següent (esquema 2).

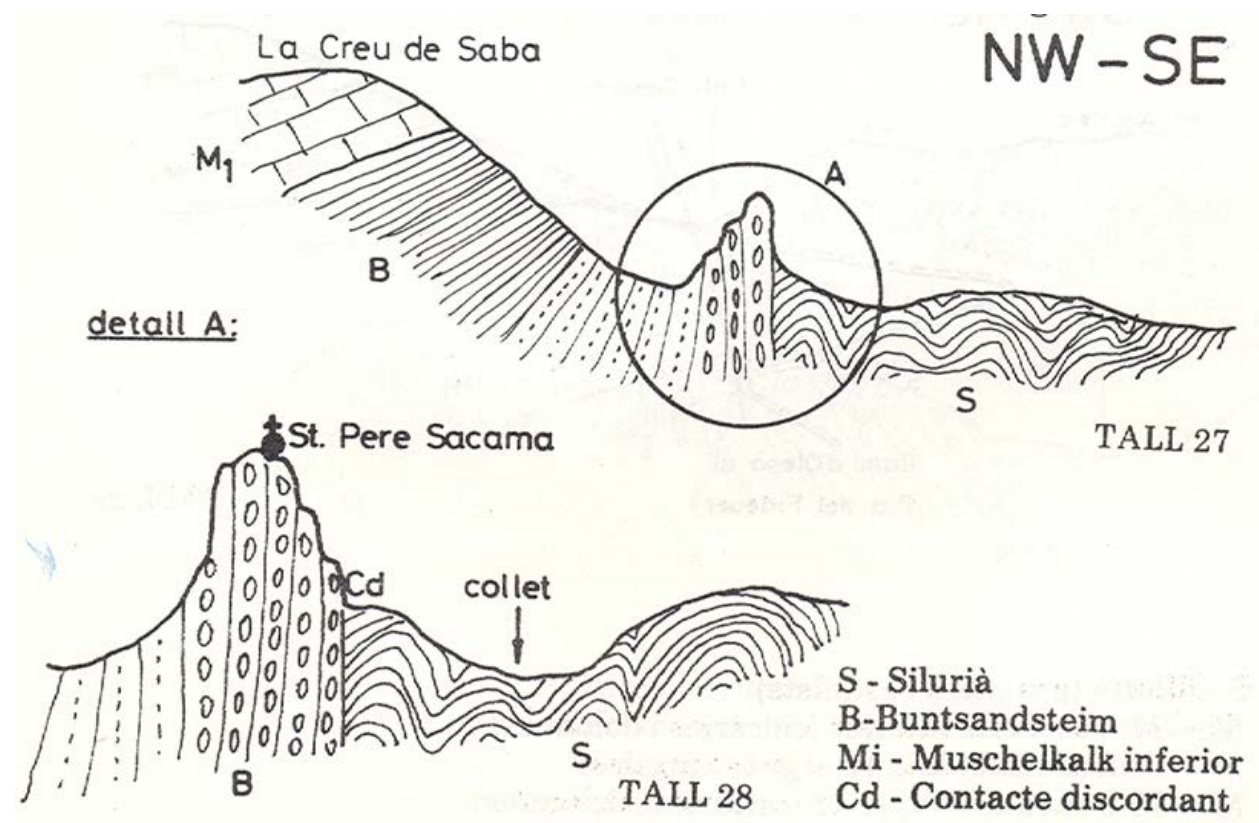

Esquema 2. Talls reproduïts de Mata-Perelló (1984a) d'Olesa de Montserrat a Ribes Blaves, a Sant Pere Sacama, al Coll Ventós i a Olesa de Montserrat 
Per d'altra banda, des d'aquest indret, i en dies de bona visibilitat, es possible gaudir d'una bona observació dels diferents sectors que constitueixen el Sistema Mediterrani. Així, es pot veure la Serra de Collserola (de la Serralada Litoral Catalana), un ampli sector de la Depressió del Vallès (Depressió Prelitoral Catalana), i també molts sectors de la Serralada prelitoral Catalana, on ara ens trobem, con la Serra de Coll Cardús, o com les Preditxes.

També es pot observar un extens sector de la Serra de l'Ubac, així com de Sant Llorenç de Munt, que pertanyen a la Depressió Geològica de l'Ebre, i més concretament als denominats Altiplans Meridionals.

Per d'altra banda, mirant cap a l'Est, es poden veure els reforçaments fets sobre l'autopista, per tal d'evitar les contínues esllavissades que s'havien anat produint durant els darrers anys, trobant-se ara aturades.( fotografia 4).

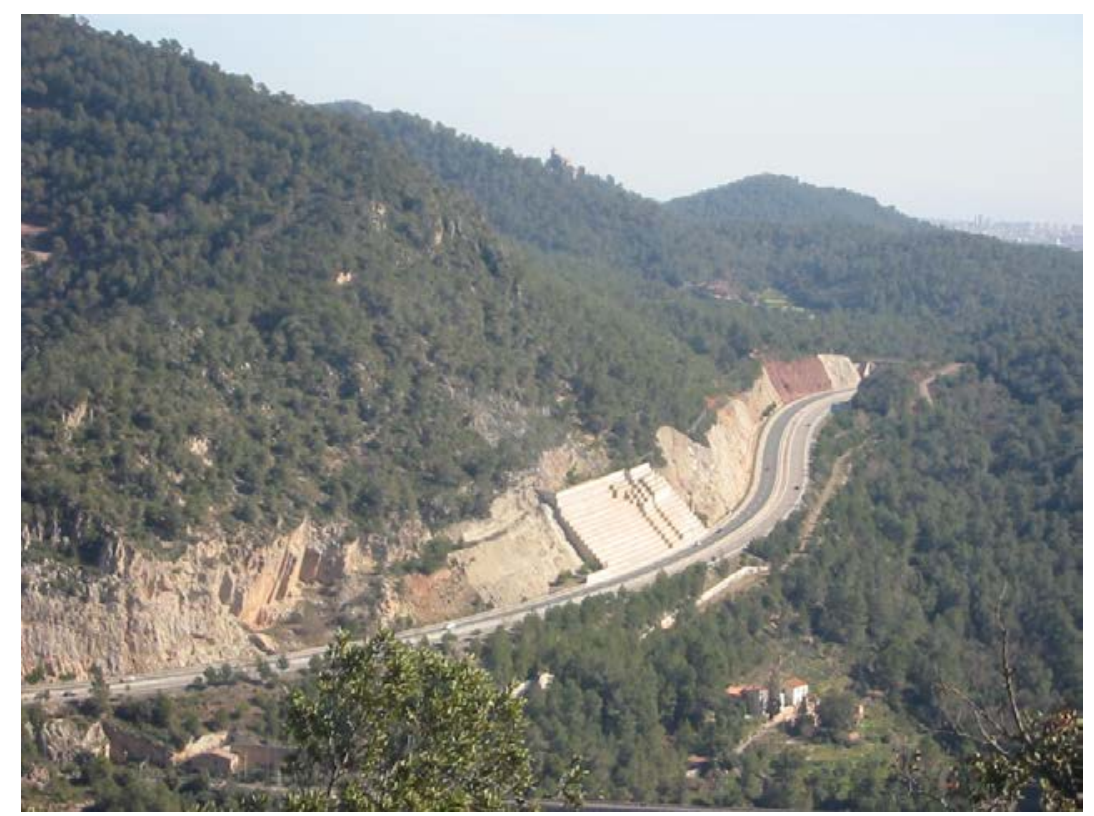

Fotografia 4. Les obres efectuades, per tal de fixar els despreniments a l'Autopista Terrassa - Manresa

\subsection{Parada 5. Coll Ventós, (terme d'Olesa de Montserrat, comarca del Baix Llobregat, subcomarca del Baix Llobregat - Nord). (Full 392).}

Des de l'anterior parada, a Sant Pere Sacama, cal agafar un caminet cap a ponent. . En arribar al Coll Ventós farem una nova aturada, a poc més de 1 ' $5 \mathrm{Km}$ de l'anteriorment realitzada.

Aquest caminet va seguint i tallant els materials del Buntsandstein, constituïts per conglomerats silícics, gresos (igualment silícics) i lulites. Sobre tots ells predominen els gresos, que presenten coloracions blanques i rogenques, les lulites per la seva banda són rogenques i contenen nivells de tonalitats verdes

Els conglomerats solament es troben al principi, prop de l'ermita. Per sobre del Coll Ventós comencen a aparèixer els nivells del Muschelkalk Inferior, constituïts per calcàries i dolomies, que pertanyen als seus estatges inferiors. Mes amunt d'aquests materials es poden veure uns trams rogencs (amb gresos, lutites i calcolutites) que pertanyen al Muschelkalk Mig. I, més 
amunt s'observen uns altres trams carbonatats (amb calcàries i dolomies), que pertanyen al Muschelkalk Superior.

Des del Coll Ventós és possible veure una falla, situada a l'altra vesant del Barranc de la Creu Beca, entre les Agulles i el Puig Cendrós. Es tracta d'una falla que posa en contacte els nivells calcaris del Muschelkalk amb els materials paleozoics del Silurià. L'esquema d'aquesta falla és (esquema 3 i fotografia 5):

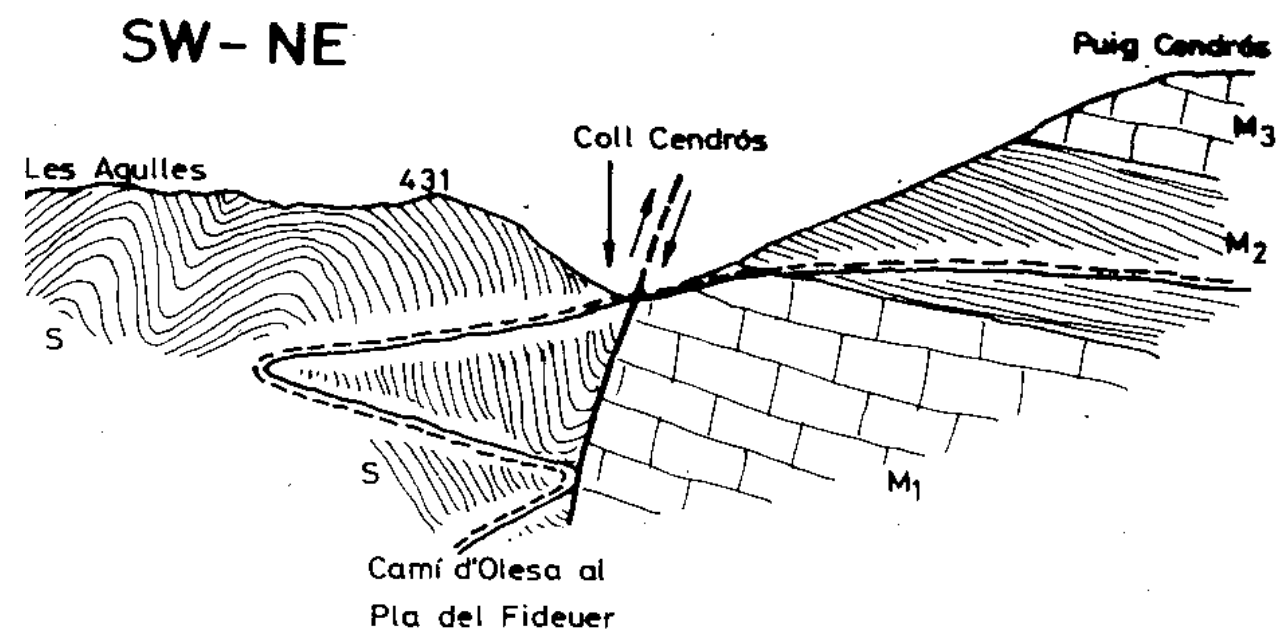

S. Silurià (psamites i esquists) i Ordovicià (pissarres i esquists)

M1. Muschelkalk Inferior (calcaries i dolomies)

M2. Muschelkalk Mig (margues, gresos i argiles)

M3. Muschelkalk Superior (calcaries i dolomies)

Esquema 3. Talls reproduïts de Mata-Perelló (1984a)

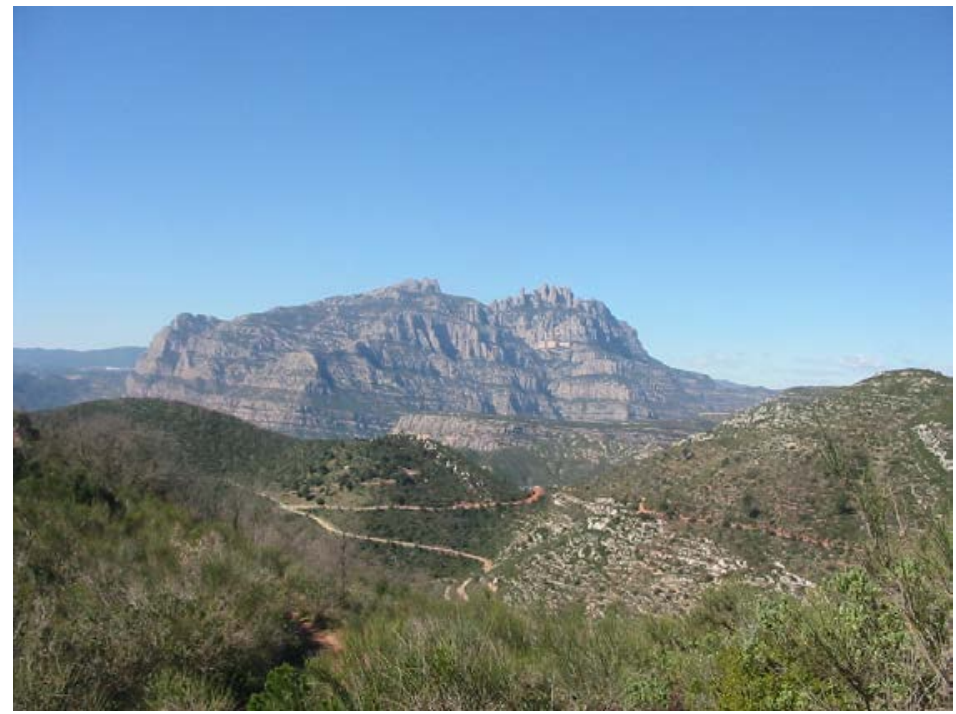

Fotografia5. Falla del Coll Ventós d’Olesa de Montserrat a Ribes Blaves, a Sant Pere Sacama, al Coll Ventós i a Olesa de Montserrat 


\subsection{Parada 6. Pla del Fideuer, (terme municipal de Vacarisses, comarca del Vallès Occidental). (Full 392).}

Des del Coll Ventós, continua el caminet que condueix cap el Pla del Fideuer, on enllaça amb el que puja des del Pont del Terme del Mimó, i amb el que ve d'Olesa. El caminet que surt del Coll Ventós, va sempre vorejant el Puig Ventós pel seu marge occidental. A poc més de 1'5 $\mathrm{Km}$, farem una nova aturada.

Durant bona part del recorregut es van trobant els nivells de Muschelkalk Inferior, constituïts per calcàries i dolomies, alternant amb petites capetes de margues. Molt sovint apareixen fucoides, entre les alçàries. En conjunt la sèrie té una clara inclinació cap el Nord.

Cap a la meitat del recorregut apareixen nivells lutitics de colors rogencs i groguencs, que pertanyen al Muschelkalk Mig. Més endavant es troben uns altres nivells calcaris i dolomítics, molt semblants als primers però del Muschelkalk Superior. Tota aquesta disposició, és perfectament visible a l'altre cantó de la Vall del Barranc de la Creu Beca, que correspon a la vessant oriental del Puig Cendrós, molt propera ja a la nostra posició.

Molt prop del Pla del Fideuer, es troba el contacte entre els materials triàsics del Muschelkalk Superior i els nivells bassals del Paleocè, formats per conglomerats i bretxes calcàries, alternant amb gresos rogencs. El contacte és mitjançant una falla inversa, que es fa palesa en indrets situats més al W, per sota de Sant Salvador de les Espases. L'esquema corresponent a aquest indret és el següent (esquema 4):

\section{SSE - NNW}

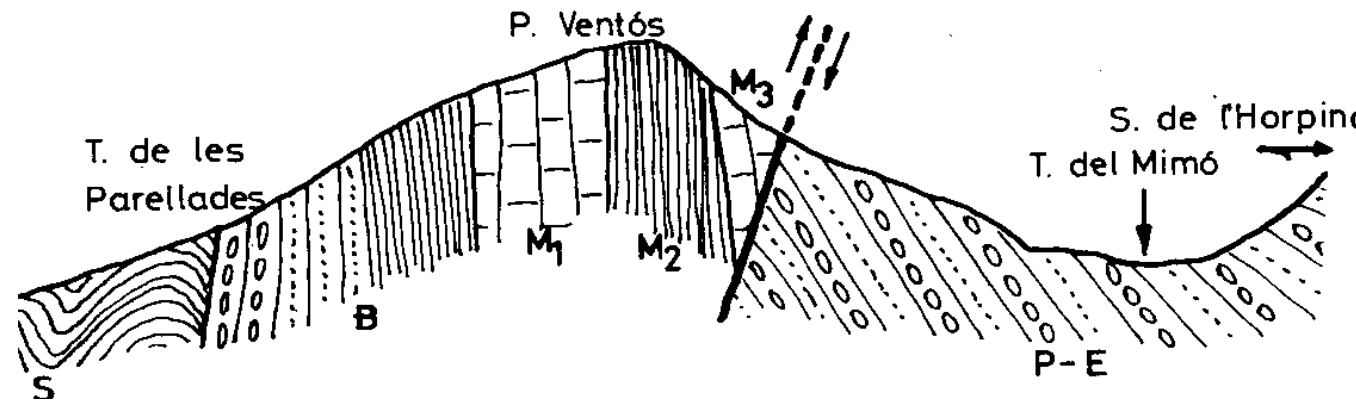

S. Silurià i Ordovicià

B. Buntsandsteim

M1. Muschelkalk Inferior (calcaries i dolomies)

M2. Muschelkalk Mig (lulites i gresos)

M3. Muschelkalk Superior (calcaries i dolomies)

P-E. Paleocé-Eocé (conglomerats i gresos)

Esquema 4. Talls reproduïts de MATA-PERELLÓ (1984a)

El Pla del Fideuer està situat sobre els materials paleocénics-eocénics rogencs, i constitueix la capçalera del Barranc de la Creu Beca, (del que hem fet esment en diferents ocasions), així com del Torrent del Mimó, excavat entre els materials terciaris. 


\subsection{Parada 7. Coll Cendrós, (terme municipal d'Olesa de Montserrat, comarca del Baix Llobregat, subcomarca del Baix Llobregat - Nord). (Full 392).}

Després de realitzar la parada anterior, cal agafar el camí que es dirigeix cap a Olesa de Montserrat, passant pel Coll Cendrós. En arribar a aquest indret farem una nova aturada, a poc més de $1 \mathrm{Km}$ de la parada anterior.

En aquest recorregut, hem anat trobant els materials esmentats a l'aturada anterior. Així, haurem vist els nivells carbonatats del Muschelkalk Superior. A mig recorregut, haurem traspassat una fractura entre aquests materials. (esquema 5).

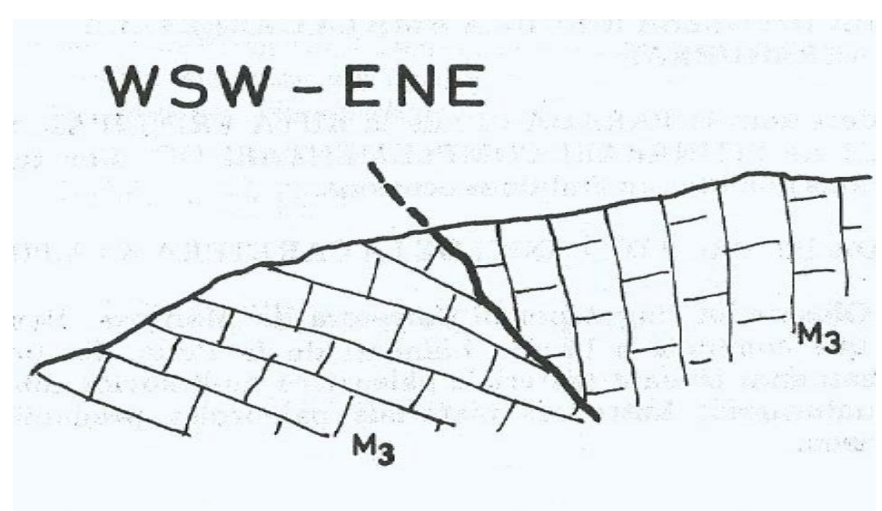

Esquema 5. Fractura entre els nivells carbonatats del Muschelkalk Superior. Talls reproduïts de Mata-Perelló (1984a)

Tot i així, prop de l'indret de l'aturada, començarem a veure afloraments dels materials rogencs del Muschelkalk Mig, amb afloraments de gresos i de calcolutites rogenques. Aquests materials, al mateix coll es troben en contacte per falla amb els del paleozoic, com s'indica a I'esquema 3, de la parada 5.

\subsection{Parada 8. Torrent de La Creu Beca, (terme municipal d'Olesa de Montserrat, comarca del Baix Llobregat, subcomarca del Baix Llobregat - Nord). (Full 392).}

Després de realitzar la parada anterior, cal continuar pel camí que es dirigeix cap a Olesa de Montserrat, baixant pel Torrent del Creu Beca. En arribar a la base del torrent, després de seguir un sinuós camí, podem fer una nova aturada, a poc més de un altre $\mathrm{Km}$ des de la parada anterior

En aquest trajecte, hem anat trobant afloraments dels materials carbonatats del Muschelkalk Inferior i també dels nivells de llicorelles paleozoiques. De fet, hem estat baixant per la falla que ha quedat representada a l'esquema 3, de la parada 5. 


\subsection{Parada 9 - condicional. Entrada a Olesa de Montserrat (terme municipal d'Olesa de Montserrat, comarca del Baix Llobregat ). (Full 392).}

Després de realitzar l'aturada anterior, cal baixar pel camí que poc a poc es va apropant a la població d'Olesa de Montserrat. En arribar-hi, farem una nova aturada, prop del Camp de Futbol. Així, haurem efectuat un recorregut descendent, proper als $4-5 \mathrm{Km}$.

En aquest recorregut, hem anat trobant els afloraments de les llicorelles paleozoiques, que fonamentalment pertanyen a I'Ordovicià i ocasionalment al Silurià. Aquests són els materials que apareixen a l'indret de l'aturada.

Molt sovint, aquests materials es troben recoberts per terrenys recents de l'Holocè, de caràcter detrític, formats pels típics derrubis de pendent.

En aquest indret finalitza l'itinerari.

\section{Referències bibliogràfiques}

GUIMERÀ, J. et altri (1992).- Geologia (II), Història Natural dels Països Catalans, Vol.2, 547 pag. Enciclopèdia Catalana, S.A. Barcelona.

MATA-PERELLÓ, J.M. (1984).- Itinerari Geològic per la Riera de Sant Jaume, la Puda i Olesa (Serralada Prelitoral). Revista Xaragall, nº 9, 31 pag. Manresa.

MATA-PERELLÓ, J.M. (1995).- Itinerari geològico-mineralògic pel Baix Llobregat: des d'Olesa de Montserrat a l'Aeri de Montserrat. Algeps, sèrie $B, n^{\circ} 4,16$ pàgines. Manresa

MATA-PERELLÓ, J.M. (1996).- Itinerari geològic per les comarques del Vallès Occidental i del Baix Llobregat: des de Viladecavalls del Vallès a Sant Pere Sacama i a Olesa de Montserrat. Inèdit, 14 pàgines. Manresa

MATA-PERELLÓ, J.M. (1999).- Itinerari geològic per les comarques del Vallès Occidental i del Baix Llobregat: des de Terrassa i Viladecavalls del Vallès a Olesa de Montserrat. Inèdit.12 pag. Manresa

MATA-PERELLÓ, J.M. (2000).- Itinerari geològic entre la riera de Sant Jaume i la Puda (termes de Viladecavalls del Vallès, Esparreguera i Olesa de Montserrat; Vallès Occidental i Baix Llobregat). Inèdit. 12 pag. Manresa

MATA-PERELLÓ, J.M. (2001).- Itinerari de recerca geològica per les comarques del Baix Llobregat i del Vallès Occidental: recorregut pels termes municipals d'Olesa de Montserrat, de Viladecavalls del Vallès i de Vacarisses. Inèdit. 14 pag. Manresa

MATA-PERELLÓ, J.M. (2005).- Recorregut de recerca geològica i mineralògica per les comarques del Baix Llobregat i Anoia: des Collbató i el Bruc a Òdena. Inèdit. 12 pag. Manresa 
MATA-PERELLÓ, J.M. (2006).- Itinerari de recerca geològica per les comarques del Baix Llobregat i del Vallès Occidental: des d'Olesa de Montserrat a Torreblanca. Inèdit. 14 pag. Manresa

MATA-PERELLÓ, J.M. (2007).- Itinerari geològic per les comarques del Vallès Occidental, Baix Llobregat i Anoia: des de Viladecavalls del Vallès a Olesa de Montserrat, Esparreguera, Collbató i al Bruc. Inèdit. 26 pag. Manresa

MATA-PERELLÓ, J.M. (2009).- Itinerari geològic per les comarques del Baix Llobregat i del Vallès Occidental: des d'Olesa de Montserrat a Ribes Blaves, a Sant Pere Sacama i a Sant salvador de les Espasses. Inèdit, 16 pàgines. Manresa

MATA-PERELLÓ, J.M. i MONTANÉ GARCÍA, P. (2005).- Sortida de recorregut geològic pel sud del Bages i pel Baix Llobregat Nord: des de Monistrol de Montserrat a Esparreguera a Olesa de Montserrat i al Cairat. Inèdit. 12 pag. Manresa

RIBA, O. et altri (1976).- Geografia Física dels Països Catalans, 205 pag. Edit. Ketres. Barcelona 